\title{
Mudança e colapso no Litoral Fluminense: os sambaquieiros e o s outros no Complexo Lagunar de Saquarema, RJ
}

\author{
Márcia Barbosa-Guimarães*
}

\begin{abstract}
BARBOSA-GUIMARÃES, M. Mudança e colapso no Litoral Fluminense: os sambaquieiros e os outros no Complexo Lagunar de Saquarema, RJ. R. Museu Arq. Etn., São Paulo, n. 21, p. 71-91, 2011.
\end{abstract}

Resumo: A pesquisa teve por objetivo compreender os grupos sambaquieiros que ocuparam o Complexo Lagunar de Saquarema entre 6.600-1.500 anos cal AP. Foi construído um modelo onde dois fatores, mudança ambiental e contato intersocietal, influenciaram o processo de transformação sociocultural verificado entre os grupos sambaquieiros. Paralelo às mudanças dos recursos e na prática de edificação dos mounds, observou-se mudança na tecnologia da indústria lítica. Associada a esta mudança tecnológica, novas práticas funerárias também foram introduzidas como a cremação e a manipulação de ossos humanos. Assim, por volta de 2.000 anos cal AP, esse contato, somado a um processo que já vinha se desenvolvendo no interior do sistema, marcou o início do colapso da sociedade sambaquiana no Complexo Lagunar de Saquarema.

Palavras-chave: Mudança social - Sociedade sambaquieira - Interação Colapso social.

\section{Introdução}

A o pensar as sociedades como sistemas abertos, a cultura material desempenha um papel fundamental na compreensão dos processos de manutenção e mudança, no quais devem ser considerados fatores exógenos e endógenos como promotores desses processos.

No caso do processo de manutenção, estudo desenvolvido sobre a identidade dos grupos pescadores e coletores, que envolveu diretamente a questão da permanência de traços comuns

(*) Núcleo de Arqueologia da Universidade Federal de Sergipe. <marcia.segal63@gmail.com>. que se mantiveram ao longo do tempo, permitiu a construção de uma identidade para esses grupos vistos como pertencentes a um sistema sociocultural (Gaspar 2003). Assim, o hábito de construir mounds conchíferos evidenciaria uma característica que parece ter sido fundamental para a estruturação da identidade social dos sambaquieiros, isto é, um propósito de edificação de um espaço onde estão em "estreita associação (...) os moradores, os mortos e os restos alimentares e industriais" (Gaspar 1995:230).

Frente às mudanças ocorridas, considerando a dinâmica do sistema sociocultural, traços identitários subsistiram ao longo do tempo. Aqui esses traços são considerados como permanências (estruturas), traços elementares das mentalidades que operam no domínio do com- 
Mudança e colapso no Litoral Fluminense: os sambaquieiros e o s outros no Complexo Lagunar de Saquarema, RJ. R. Museu Arq. Etn., São Paulo, n. 21, p. 71-91, 2011.

portamento e que se perpetuam na longa duração (Vouvelle 1993). Essas estruturas identitárias resistem às mudanças, embora não as impeçam de ocorrer, apenas retardam-nas, imprimindo-lhes um ritmo tão lento que, muitas vezes, parecem estruturas imóveis. Nesse sentido, Dias e Carvalho (1995) também ressaltam essa característica, ao tratar da aparente imobilidade da tradição Itaipu, que consideram reflexo dos aspectos tradicionais dos grupos a ela relacionados. Sendo tradicionais seriam mais visíveis em oposição aos elementos inovadores. Embora Gaspar (2003, 1995) e Dias e Carvalho (1995) tenham tratado das permanências, essas foram percebidas em diferentes escalas pelos autores: enquanto para a primeira foram instrumentos que possibilitaram delinear um amplo sistema sociocultural macro-regional, para os outros autores serviram para perceber traços identitários de grupos locais.

Assim, permanências e mudanças são componentes de um processo dinâmico e não devem ser consideradas como polos opostos em estudos regionais. No caso específico da sociedade sambaquiana do litoral fluminense, tanto as permanências como as mudanças foram abordadas isoladamente em estudos anteriores, o que contribuiu para uma aparente visão de imobilidade social, traduzida na ênfase aos aspectos tradicionais de uma sociedade e, por outro lado, por uma fragilidade sociocultural, influenciada pelas características generalizadoras do conceito de bandos nômades aplicado a esses grupos (Barbosa-Guimarães 2003). Soma-se, ainda, que embora tenha sido focado pela escola neo-evolucionista, o estudo sobre mudança cultural dedicou-se à construção de um modelo unifatorial (fator de ordem ambiental).

Assim é que, na mesma medida verificada para os estudos sobre permanências socioculturais, no curso da trajetória intelectual, o processo intra e intersocietal de mudança social era visto como incompatível, parte de um arsenal de forças opostas. Tal oposição não é verdade. Não existem razões satisfatórias para que ambos os processos, internos e externos, não possam ser incorporados em modelos de mudança cultural. Existem, de fato, muitas razões para acreditar que modelos que não tentam incorporá-los resultem em vias simplistas e irreais de mudança (Schortmann \& Urban 1987).

Tendo em conta a sociedade de pescadores e coletores do Complexo Lagunar de Saquarema, fatores endógenos não foram possíveis de serem mapeados, de forma mais detalhada, enquanto alavanca do processo de mudança sociocultural. Acreditamos que, embora esses tenham ocorrido e está claro que o aumento da densidade populacional exerceu um papel de agenciador endógeno da mudança sociocultural (Gaspar 2003; Hassan 1978; Machado 1991; Uchoa et al. 1989), o peso da tradição extremamente bem sucedida acabou por camuflar traços de mudança. Soma-se, ainda, a raridade de estudos que considerem fatores endógenos no processo de mudança sociocultural em sistemas igualitários, nos quais status é determinado, na sua grande maioria, por sexo/idade. Estudos sobre status social são mais raros, embora um movimento nesse sentido tenha se iniciado junto aos estudos sobre a sociedade sambaquiana (Escórcio \& Gaspar 2004).

Assim, fatores exógenos, como alteração ambiental e contato intersocietal, foram considerados relevantes como promotores de mudança no sistema sociocultural dos pescadores e coletores do Complexo Lagunar de Saquarema, tendo sido abordados a partir da análise multifatorial.

Em relação às alterações ambientais, buscou-se ir além da perspectiva do funcionalismo ecológico e mesmo da vertente neo-evolucionista da arqueologia processual, nas quais mudança sociocultural é sinônimo de resposta adaptativa. Relativizou-se o papel desempenhado pela adaptação no processo de mudança sociocultural. Nesse caso, opondo-se ao neo-evolucionismo binforniano, avançou-se na compreensão dos padrões de interação socioambiental, nos quais diferentes fatores, não somente o ecológico, foram considerados no estudo da mudança (Willey 1953). Ademais, foi estabelecida a unidade de estudo, considerada aqui o agrupamento de sítios e não sítios isolados. Assim, as relações socioambientais dos pescadores e coletores ocorriam via exploração conjunta do território e não da área de entorno dos sítios (Gaspar 2003). Além de tudo, partilha-se da opinião de que nem todos os aspectos de um sistema 
sociocultural são afetados por fatores ambientais. Enquanto os subsistemas de subsistência e de tecnologia são diretamente influenciados por fatores ecológicos, as estruturas social e ideológica são mais resistentes.

De qualquer forma, embora não se questione a importância das mudanças ambientais como agente catalisador de mudanças socioculturais, os dados paleoambientais disponíveis não apontam para mudanças drásticas na vegetação da Região dos Lagos durante o período entre 3.600 a 3700 anos cal AP. De acordo com Schell-Ybert $(2000,2001)$ a vegetação de restinga se manteve, com variações observadas apenas no ecossistema de mangue. Entretanto, períodos de maior ou menor umidade devem ter influenciado mudanças do ponto de vista conjuntural, e estas foram possíveis de serem verificadas nos vestígios macrofaunísticos.

No caso do contato intersocietal, buscou-se apoio no arcabouço teórico proposto por Schortmman e Urban (1987). O contato intersocietal foi estabelecido a partir da introdução de novos itens (cerâmica), de novas tecnologias (apurado domínio da técnica de lascamento do quartzo) e de práticas funerárias (cremação) no sistema sociocultural dos pescadores e coletores, tendo um maior peso no processo de mudança sociocultural, as variáveis tecnológica e simbólica sendo, contudo, impossível clarificar as relações que estavam envolvidas. $O$ contato entre os grupos de pescadores e coletores e os grupos ceramistas Tupinambá e da tradição Una parece ter ocorrido em condições desfavoráveis para os primeiros, pois suas características antibelicistas não lhes forneceram aporte capaz de organizar uma resposta que impedisse ou limitasse as incursões dos grupos ceramistas, portadores de uma organização social mais complexa. Assim, frente ao contato, a sociedade sambaquiana, unidade de análise escolhida para se compreender o contato intersocietal, entrou em colapso.

O fator exógeno - o contato intersocietal caracterizado pelos movimentos populacionais dos grupos ceramistas em direção ao litoral - foi o principal fator perseguido pelo projeto enquanto promotor da mudança social. E, nesse caso, embora a introdução da cerâmica seja um item diferencial no aparato tecnológico dos pescado- res e coletores, concordamos com Dias e Carvalho (1980) quando afirmam que esse item foi integrado ao seu acervo sem que tenham sido observadas quedas nas frequências dos itens tradicionais dessas sociedades. Embora introduzida via contato intersocietal, a cerâmica recuperada no período tardio da ocupação sambaquiana, como variável isolada, pouco informou sobre mudança sociocultural possibilitando, apenas a partir de estudos morfo-tecnológicos, associá-la aos grupos nativos portadores das características da tradição ceramista Una.

Contudo, a introdução da cerâmica foi vista em um contexto mais amplo que o meramente tecnológico. Ela foi um elemento de contato, possivelmente, de uma pequena rede de trocas, a julgar pela sua dispersão territorial, frequência e limite cronológico, nas quais além do objeto, o sujeito teria uma participação ativa, considerando, principalmente, que essas redes foram construídas a partir de alianças territoriais ao invés de conflitos (sobre conflitos na sociedade sambaquiana ver Lessa e Medeiros 2001).

Entretanto, em relação à mudança sociocultural a partir de fatores exógenos, as práticas mortuárias observadas nos sítios do Complexo Lagunar de Saquarema foram os verdadeiros alicerces sobre o quais se construiu a hipótese de trabalho. Esse item se sustentou na idéia de que as práticas funerárias são elementos estruturais e, portanto, estão relacionadas ao universo simbólico, às cosmogonias, ao que de mais profundo ordena um sistema sociocultural, tendo um apego enorme às continuidades e sendo resistentes às mudanças de curto e médio prazo. Quando comprovada a mudança nessa estrutura ela foi compreendida na longa duração. Por outro lado, adotamos o pressuposto de Hodder (1982) de que para se determinar o significado social de práticas funerárias, outros aspectos do registro arqueológico devem ser examinados, como o padrão de assentamento. Assim, a adoção da prática da cremação funerária foi entendida como o ápice de um processo que se desenrolou a partir do contato intersocietal (Barbosa-Guimarães et al. 2005/2006). Tal como a cerâmica e a tecnologia de debitagem do quartzo, a cremação foi uma adoção cultural de práticas exercidas por grupos portadores da 
cerâmica classificada como tradição Una, que ocupavam territórios na região serrana e que, a partir de 1.500 anos cal AP, aproximadamente, iniciaram o processo de fixação no litoral.

Construído o modelo de mudança sociocultural a partir do contato intersocietal, os estudos foram encaminhados, por um lado, no sentido de verificar não só as mudanças, mas quão profundas elas foram ao buscar identificar a emergência de novas unidades socioculturais (sítio Ilha dos Macacos e sambaqui da Pontinha), o papel desempenhado por aquelas na formação dessas novas unidades e o colapso das unidades originais (Robrahn-Gonzalez 1998; Renfrew 1984).

A questão do colapso se impõe na medida em que se assume que representou um sistema que conduziu à mudança social. Embora o conceito tenha sido forjado por Renfrew (1984), a partir dos estudos em sociedades complexas e hierarquizadas, como no caso da sociedade Maia, buscou-se elaborar um sistema de colapso que fosse pertinente às sociedades igualitárias, tendo como estudo de caso a sociedade sambaquiana. Dessa forma, o sistema de colapso se constituiu em dois momentos distintos: o período do colapso no qual foi possível vislumbrar mudanças no padrão de assentamento, na construção dos mounds, nas práticas funerárias e na tecnologia; e o momento após o colapso, que foi observado a partir da adoção da cremação como prática funerária única e o fim da tradição de construir mounds (conchíferos ou terrosos).

\section{Material e métodos}

Uma análise sistemática da bibliografia disponível para a área de estudo indicou a presença de vinte e quatro sítios arqueológicos distribuídos no Complexo Lagunar de Saquarema. Os resultados permitiram observar dois conjuntos diferenciados de informações: um primeiro, no qual as informações eram de caráter genérico, sendo resultado das pesquisas assistemáticas realizadas na área piloto nas décadas de 40 e 60; e outro, no qual as informações eram detalhadas resultado das pesquisas sistemáticas desenvolvidas a partir do final década de 80 .
Diante destes resultados, no qual alguns atributos considerados fundamentais para o desenvolvimento da pesquisa estavam quantitativa e qualitativamente insatisfatórios, optamos por realizar pesquisa de campo buscando revisitar alguns dos sítios descritos na bibliografia com a finalidade de complementar as lacunas existentes e avaliar sítios passíveis de intervenção, visando aumentar a amostragem. Tal investigação apoiou-se, também, nas informações disponíveis no cadastro de sítios arqueológicos do Instituto de Patrimônio Histórico e Artístico Nacional (IPHAN) que demonstravam uma lacuna no tocante às prospecções arqueológicas: apenas três sítios foram registrados após as pesquisas desenvolvidas no final da década de 60. Assim, revisitamos dezoito dos vinte e quatro sítios descritos para a região, sendo que apenas quinze encontravam-se cadastrados no IPHAN. Durante a etapa de campo de 2003, sete sítios não foram localizados e quatros novos sítios foram encontrados (Ilha dos Macacos, Itaúnas, Mombaça I e Ponta dos Anjos) (Fig. 1).

Assim, nossa análise associou dados secundários (bibliográficos) e dados primários (análise de material arqueológico recuperados nos sítios pesquisados). Considerando todos os limites e possibilidades para seleção da amostra foram escolhidos doze do total de vinte e sete sítios identificados na bibliografia e na prospecção, a saber: Saquarema, Pontinha, Beirada, Moa, Manitiba I, Madressilva, Saco, Itaúnas, Jaconé, Mombaça I, Ilha dos Macacos e Bravo. Estes doze sítios forneceram trinta e quatro camadas estratigráficas, nossa unidade de análise.

A aplicação do teste de cluster, método hierárquico, permitiu sistematizar as informações para as trinta e quatro camadas estratigráficas identificadas nos doze sítios da amostra, através da análise de dez atributos e sessenta e seis variáveis (Fig. 2). Como resultado da aplicação da análise multivariável, as trinta e quatro camadas estratigráficas foram agrupadas em dois conjuntos (Fig.3).

A análise multivariável foi realizada através do uso do software PAST - Paleontological Statistics software package for education, versão 2.02 (Hammer et al. 2001) (Fig. 4). 


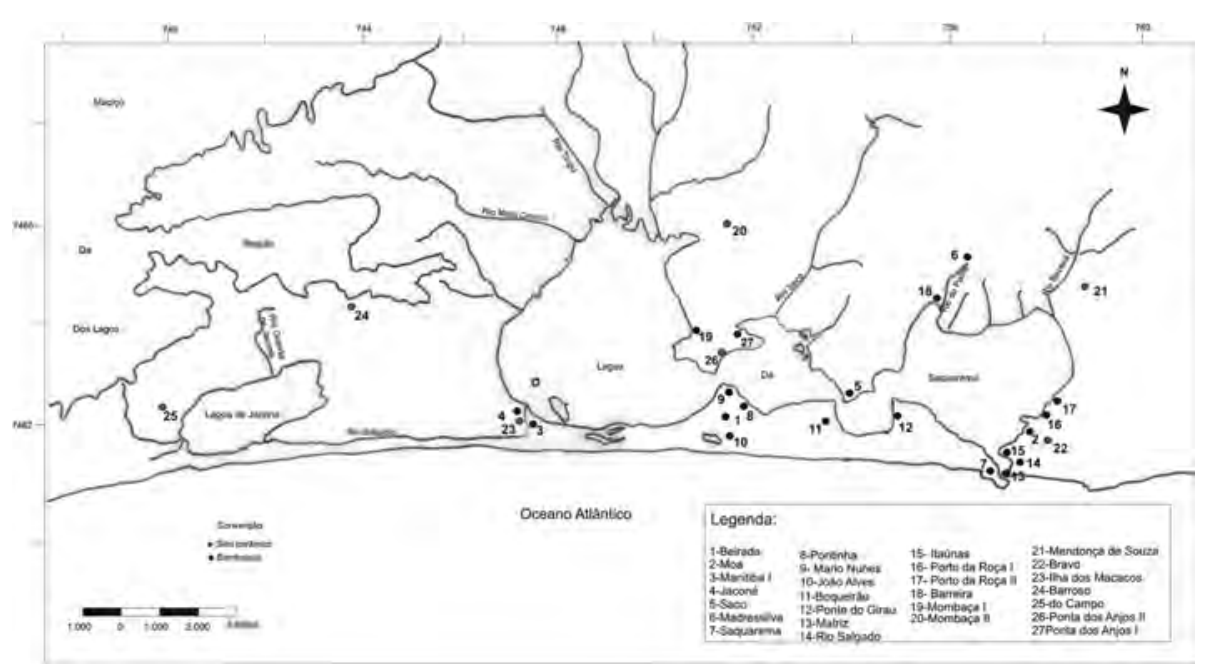

Fig. 1. Mapa de distribuição dos sítios arqueológicos do Complexo Lagunar de Saquarema. Fonte: Folhas IBGE 23-Z-B-VI-3 e SF-2-B-V-4. Escala 1:50.000.

Efetuamos a calibração das datações absolutas disponíveis em Kneip (2001), visando fornecer maior acuidade aos dados cronológicos (Fig. 5). Para tanto, utilizamos o software Calib - Radiocarbon Calibration Program, versão 6.2, em associação com Stuiver e Reimer (1993).

\section{Resultados}

A análise de cluster permitiu observar a existência de dois grandes agrupamentos: o agrupamento $\mathrm{A}$, mais antigo, formado pelos sítios Itaúnas, Manitiba, Beirada, Mombaça, Jaconé, Madressilva e camadas III e II do sítio do Moa, e que foi interpretado como representando as unidades geradoras ou originais, ou seja, os grupos pescadores e coletores construtores de sambaquis; e um mais recente, formado pelos sítios Pontinha, Saquarema, Ilha dos Macacos, Bravo, Saco e camada I do sítio do Moa, interpretados como novas unidades socioculturais, seja aqueles que guardam traços relacionados aos grupos originais - apresentam uma economia de pescadores e coletores - seja aqueles identificados como novos grupos e que não apresentam características que possam relacioná-los aos grupos originais, sendo representados por grupos agricultores e ceramistas.
Todos os sítios representantes dos grupos com economia de pescadores e coletores apresentaram um mesmo padrão de implantação, com predominância, quase que total, para a implantação sobre cordão arenoso ou duna; para a proximidade com recursos aquáticos, notadamente a laguna de Saquarema, na faixa de $500 \mathrm{~m}$ de distância máxima; e por fim, a proximidade de recursos minerais, notadamente líticos, obtidos tanto nos depósitos coluviais de alto gradiente, ricos em seixos e blocos de rochas graníticas, gnáissicas e básicas, quanto nas áreas de planície de inundação e de rampas terraços, constituídos predominantemente por materiais clásticos de litologias diferentes, inclusive sílex, na faixa entre 500 a 2000m de distância. Kneip (2001) observa que a proximidade com a área-fonte de matéria-prima lítica não constitui um fator preponderante para a escolha do local de implantação dos sítios de pescadores e coletores. Observação que reiteramos.

A distribuição das datações calibradas dos sítios de pescadores e coletores permitiu observar momentos em que o abandono de um sítio marcava o início da construção de outro. Assim, a formação de núcleos de sítios (sítios muito próximos e concomitantes) não foi observada, sendo o agrupamento de sítios a reocupação de pontos estratégicos da laguna de Saquarema, num ciclo construtivo de longa duração (Fig. 6). 


\begin{tabular}{|c|c|}
\hline ATRIBUTOS & VARIÁVEIS \\
\hline 1) Matriz sedimentar & $\begin{array}{l}\text { - Mineral-organica } \\
\text { 2- Conchífera } \\
3 \text { - Mineral-organica com lente e/ou bolsões de conchas } \\
4 \text { - Indeterminada }\end{array}$ \\
\hline 2) Composição malacológica & $\begin{array}{l}1 \text { - A. brasiliana } \\
2 \text { - Ostrea sp } \\
3 \text { - L. Pectinata } \\
4 \text { - Ostrea/A. brasiliana } \\
5 \text { - Mytilidae } \\
6 \text { - L. pectinata/A. brasiliana } \\
7 \text { - Mytilidae/L. pectinata } \\
8 \text { - Thais haemastona/ Mytilidae } \\
9 \text { - Ausente } \\
10 \text { - Indeterminada }\end{array}$ \\
\hline 3) Composição ictiológica & $\begin{array}{l}\text { 1- Ariidae } \\
2 \text { - Scianidae } \\
\text { 3- Ariidae/ Scianidae } \\
4 \text { - Ausente } \\
5 \text { - Indeterminada }\end{array}$ \\
\hline 4) Indústria lítica & $\begin{array}{l}1 \text { - Lascada } \\
2 \text { - Sobre seixos } \\
\text { 3 - Lascada e sobre seixos } \\
\text { 4- Indeterminada } \\
5 \text { - Ausente }\end{array}$ \\
\hline 5) Indústria óssea & $\begin{array}{l}1 \text { - Pontas } \\
2 \text { - Espinhos de peixe trabalhados } \\
3 \text { - Pontas e espinhos } \\
4 \text { - indeterminada } \\
5 \text { - Ausente }\end{array}$ \\
\hline 6) Cerâmica & $\begin{array}{l}1 \text { - Tradição Una } \\
2 \text { - Tradição Tupinambá } \\
3 \text { - Tradição Neobrasileira } \\
4 \text { - Tradição Una/Neobrasileira } \\
5 \text { - Tradição Tupinambá/Neobrasileira } \\
6 \text { - Indeterminada } \\
7 \text { - Ausente }\end{array}$ \\
\hline 7) Cronologia & $\begin{array}{l}1-5.000 \text { a } 4.000 \text { anos cal AP } \\
2-3.999 \text { a } 3.800 \text { anos cal AP } \\
3-3799 \text { a } 3.700 \\
4-3699 \text { a } 3.600 \\
5-3599 \text { a } 3.300 \\
6-3.300 \text { a } 2.000 \text { anos cal AP } \\
7-1999 \text { a } 1.500 \text { anos cal AP } \\
8 \text { - Pós } 1.499 \text { anos cal AP } \\
9 \text { - Indeterminada }\end{array}$ \\
\hline 8) Sepultamentos predominantes & $\begin{array}{l}1 \text { - Cremados primários/secundários } \\
2 \text { - Primários/secundários não cremados } \\
2 \text { - Secundários com manipulação de ossos } \\
3 \text { - Secundários em fogueiras crematórias } \\
4 \text { - Em urnas } \\
5 \text { - Ausente } \\
6 \text { - Indeterminado }\end{array}$ \\
\hline
\end{tabular}

Fig. 2. Atributos e variáveis da análise multivariável. 


\begin{tabular}{ccccccccc}
\hline & 1 & 2 & 3 & 4 & 5 & 6 & 7 & 8 \\
\hline \hline MAN 1 & 1 & 1 & 1 & 1 & 1 & 5 & 8 & 5 \\
MAN2 & 2 & 1 & 2 & 2 & 2 & 5 & 7 & 5 \\
MAN3 & 1 & 4 & 2 & 4 & 2 & 5 & 6 & 5 \\
MAN4 & 2 & 2 & 3 & 1 & 3 & 5 & 5 & 5 \\
MAN5 & 2 & 2 & 2 & 2 & 2 & 5 & 4 & 5 \\
MAN6 & 2 & 2 & 2 & 4 & 3 & 5 & 3 & 2 \\
MAN7 & 1 & 2 & 1 & 1 & 2 & 5 & 2 & 2 \\
BEI1 & 1 & 1 & 2 & 2 & 2 & 5 & 11 & 2 \\
BEI2 & 2 & 2 & 2 & 2 & 2 & 5 & 5 & 2 \\
BEI3 & 2 & 2 & 2 & 2 & 2 & 5 & 4 & 2 \\
BEI4 & 2 & 2 & 2 & 2 & 2 & 5 & 3 & 2 \\
MOA1 & 1 & 3 & 2 & 2 & 2 & 1 & 6 & 2 \\
MOA2 & 2 & 3 & 2 & 2 & 2 & 5 & 5 & 5 \\
MOA3 & 1 & 3 & 2 & 2 & 2 & 5 & 4 & 2 \\
PON1 & 1 & 1 & 1 & 1 & 1 & 1 & 11 & 2 \\
PON2 & 1 & 1 & 1 & 1 & 1 & 5 & 9 & 1 \\
PON3 & 1 & 1 & 1 & 1 & 1 & 5 & 9 & 1 \\
PON4 & 1 & 1 & 1 & 1 & 1 & 5 & 8 & 1 \\
SAC & 1 & 2 & 1 & 1 & 1 & 1 & 7 & 5 \\
MAD & 1 & 2 & 1 & 1 & 1 & 5 & 6 & 5 \\
JAC1 & 1 & 2 & 2 & 3 & 4 & 5 & 6 & 5 \\
JAC4 & 2 & 2 & 2 & 1 & 3 & 5 & 4 & 5 \\
\hline ITA4 & 1 & 2 & 2 & 2 & 2 & 5 & 1 & 2 \\
MOM1 & 1 & 1 & 2 & 4 & 1 & 5 & 11 & 5 \\
MOM2 & 2 & 1 & 2 & 4 & 1 & 5 & 11 & 5 \\
ILHA & 1 & 4 & 1 & 1 & 1 & 1 & 11 & 3 \\
SAQ1 & 1 & 5 & 5 & 1 & 1 & 1 & 11 & 5 \\
SAQ3 & 1 & 5 & 5 & 1 & 1 & 5 & 6 & 2 \\
SAQ2 & 2 & 1 & 5 & 1 & 1 & 5 & 7 & 2 \\
BRAV & 1 & 4 & 4 & 4 & 4 & 2 & 11 & 4
\end{tabular}

Fig. 3. Planilha da análise multivariável.

O agrupamento $\mathrm{A}$, de acordo com os dados cronológicos, teria no sambaqui de Itaúnas a ocupação mais antiga, com sua camada IV datada entre 6.726 e 6.356 anos cal AP. Neste período devemos observar que o nível do mar encontrava-se a aproximadamente $1,5 \mathrm{~m}$ acima do nível atual, o que propiciava a implantação do sambaqui sobre uma duna na porção leste da laguna. Esse grupo era portador de uma tecno- logia óssea com leve predomínio dos artefatos confeccionados sobre espinhos de peixes, de uma indústria lítica com base nos seixos utilizados, da pesca de representantes do genero Micropogonias e da coleta da espécie Anomalocardia brasiliana (Gmelin) e do genero Ostrea, embora os vestígios faunísticos apresentassem baixa frequencia total. Embora não esteja disponível datação para as camadas subsequentes do sambaqui de Itaúnas, acreditamos que este tenha sido abandonado por volta de 6.000 anos cal AP, devido à subida do nível do mar.

A reocupação da laguna de Saquarema teria ocorrido entre 4.980 e 4.718 anos cal AP, quando o nível do mar começa sua lenta descida, estando representada pela implantação do grupo sambaquieiro na faixa externa da laguna, através do sambaqui de Manitiba I (camada VII). A ocupação do Manitiba I teve por marco construtivo um evento mortuário ocorrido na camada basal. Assim, na camada mais antiga, além do sepultamento estavam presentes objetos e estruturas relacionadas à parafernália ritual. $\mathrm{O}$ conjunto de artefatos estava caracterizado pelo predomínio de pontas ósseas e dos seixos utilizados, bem como por uma fauna ictiológica marcada por restos de representantes da família Ariidae, e por uma fauna malacológica com predomínio de espécies de mangue como Brachidontes exustus (Linnaeus).

No período entre 4.700 e 4.300 anos cal AP, continuou a ocupação do sambaqui de Manitiba I (camadas VI e V) e foi edificado na restinga externa, a $4 \mathrm{~km}$ de distancia, em direção leste, o sambaqui da Beirada. Este período apresenta um conjunto de ocupações extremamente homogêneo com predomínio de seixos utilizados e dos artefatos ósseos confeccionados sobre espinhos de peixes; predomínio da pesca de representantes do genero Micropogonias e coleta de espécimes dos genero Ostrea e da família Mytilidae, demonstrando a presença de mangue nas proximidades dos sambaquis.

No período entre 4.299 e 3.800 anos cal AP, ocorreu a ocupação inicial do sambaqui do Moa (camada III) e do sambaqui de Jaconé (camada IV), e as ocupações finais do sambaqui de Manitiba (camadas IV a II). Todos os 


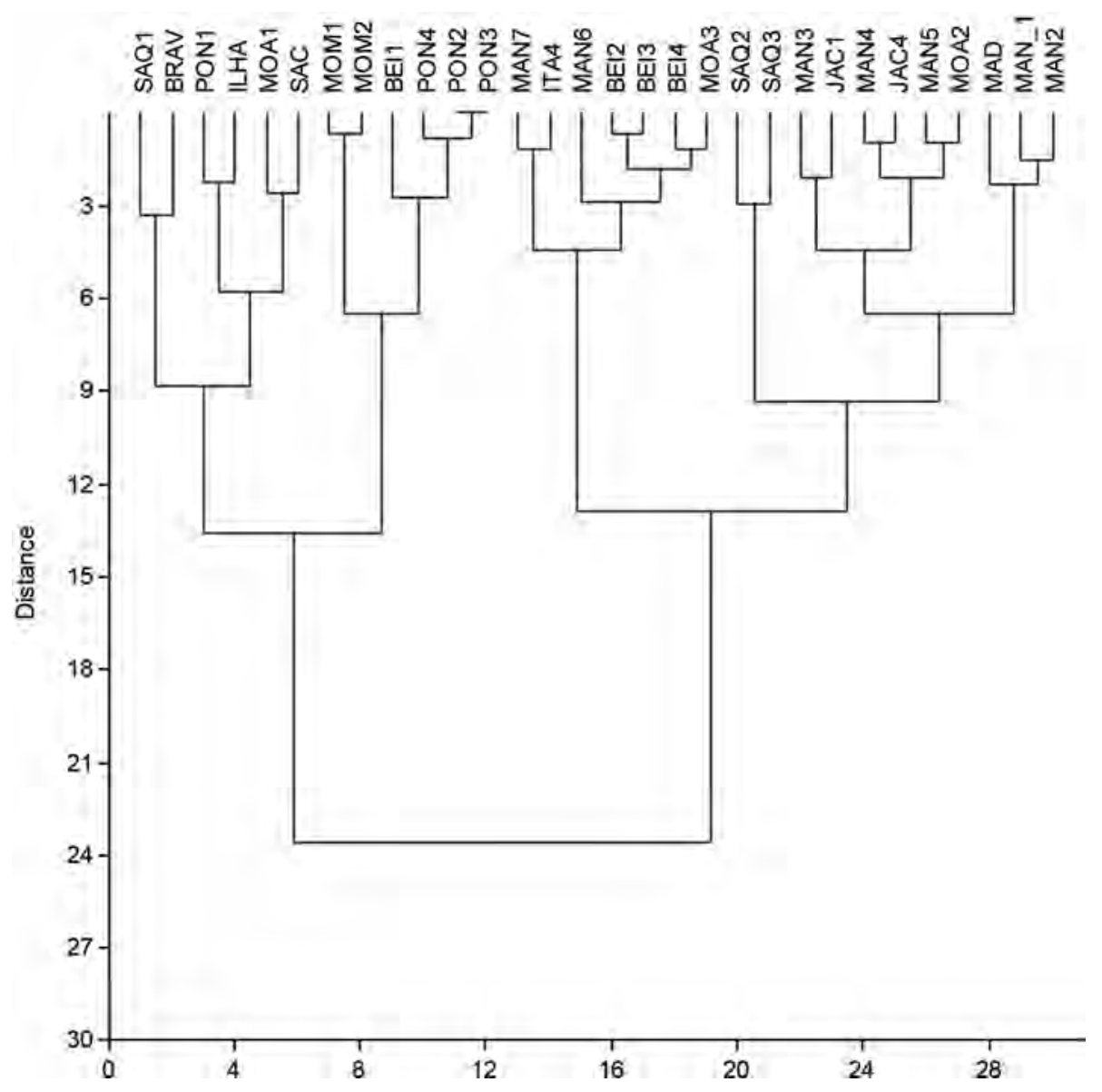

Fig. 4. Dendrograma.

sambaquis deste período são concomitantes, exceção ao sambaqui de Manitiba I que é abandonado um pouco antes do início da ocupação do sambaqui de Jaconé. A ocupação do Jaconé foi concomitante à continuação da ocupação do Beirada (camada III). A diversidade e abundância de espécies malacológicas se mantiveram semelhante ao momento anterior, com predomínio de representantes oriundos do mangue - Ostrea sp e Lucina pectinata (Gmelin), enquanto os ocupantes do sambaqui do Moa (camada III), tinham na coleta da espécie Stramonita haemastona (Linnaeus) e família Mytilidae, sua preferência. A pesca de representantes do genero Micropogonias também prevaleceu, além da indústria lítica sobre seixos utilizados e da indústria óssea sobre espinhos de peixes.
Entre 3.799 e 3.700 anos cal AP, o mangue continuava ativo nas margens da laguna de Saquarema, e o predomínio de ostreídeos foi observado nas matrizes conchíferas dos sambaquis da Beirada (camada II) e Jaconé (camadas III e II). Na margem leste da laguna, no sambaqui do Moa (camada II), a espécie S. haemastona manteve-se predominante. A indústria lítica apresentou baixíssima frequência total com predomínio para os seixos utilizados. A indústria óssea continua a ser dominada pelos espinhos de peixes trabalhados.

Porém, entre 3.699 e 3.600 anos cal AP, com o possível final da ocupação dos sambaquis do Moa (camada I), a continuação da ocupação dos sambaquis de Jaconé (camada II) e Beirada (camada I), e o início da ocupação dos sambaquis da Madressilva (camada inferior) e 


\begin{tabular}{|c|c|c|c|c|}
\hline SíTIOS & $\begin{array}{c}\text { REFERENCIA } \\
\text { ESTRATIGRÁFICA }\end{array}$ & $\begin{array}{l}\text { DATAÇÕES } \\
\text { ABSOLUTAS }\end{array}$ & $\begin{array}{c}{ }^{* *} \text { DATAÇÕES } \\
\text { CALIBRADAS } \\
1 \text { SIGMA (CAL BP) }\end{array}$ & $\begin{array}{c}{ }^{* *} \text { DATAÇÕES } \\
\text { CALIBRADAS } \\
2 \text { SIGMA (CAL BP) }\end{array}$ \\
\hline Madressilva & Camada basal & $3640 \pm 50$ & $3469-3606$ & $3410-3677$ \\
\hline \multirow[t]{7}{*}{ Manitiba I } & Camada I & $3810 \pm 70$ & $4089-4296$ & $4068-4416$ \\
\hline & Camada II & $3900 \pm 70$ & $4235-4424$ & $4147-4452$ \\
\hline & Camada III & $3940 \pm 50$ & $4345-4440$ & $4239-4522$ \\
\hline & Camada IV & $3970 \pm 70$ & $4318-4526$ & $4226-4624$ \\
\hline & Camada V & $4030 \pm 70$ & $4417-4585$ & $4378-4726$ \\
\hline & Camada VI & $4130 \pm 70$ & $4569-4712$ & $4514-4837$ \\
\hline & Camada VII & $4270 \pm 70$ & 4809-4892 & $4781-4980$ \\
\hline Saco & Camada basal & $3540 \pm 50$ & $3358-3480$ & $3318-3560$ \\
\hline \multirow[t]{2}{*}{ Jaconé } & Camada I & $3350 \pm 80$ & $2973-3391$ & $3109-3322$ \\
\hline & Camada IV & $3760 \pm 70$ & $3610-3802$ & $3510-3881$ \\
\hline \multirow[t]{2}{*}{ Saquarema } & Camada II & $2550 \pm 60$ & $2501-2595$ & $2453-2765$ \\
\hline & Camada III & $3280 \pm 60$ & $3443-3579$ & $3381-3639$ \\
\hline \multirow[t]{2}{*}{ Moa } & Camada I & $3610 \pm 190$ & $3299-3772$ & $3019-4006$ \\
\hline & Camada II & $3960 \pm 200$ & $3689-4226$ & $3451-4491$ \\
\hline \multirow[t]{3}{*}{ Pontinha } & Camada II & $1790 \pm 50$ & $1691-1747$ & $1569-1825$ \\
\hline & Camada II & $1810 \pm 40$ & $1708-1810$ & $1686-1829$ \\
\hline & Camada IV & $2270 \pm 170$ & $2044-2488$ & $1923-2737$ \\
\hline \multirow[t]{4}{*}{ Beirada } & Camada I & $3800 \pm 190$ & $3490-3982$ & $3305-4279$ \\
\hline & Camada II & $4160 \pm 180$ & $3763-4729$ & $3973-4451$ \\
\hline & Camada III & $4300 \pm 190$ & $4159-4684$ & $3882-4885$ \\
\hline & Camada IV & $4520 \pm 190$ & $4336-4943$ & $4221-5255$ \\
\hline Itaúnas & Fogueira da camada IV & $5700 \pm 70$ & - & $6726-6356$ \\
\hline *Mombaça I & Base da camada II & $3900 \pm 50$ & - & $2540-2270$ \\
\hline $\begin{array}{l}\text { *Ilha dos } \\
\text { Macacos }\end{array}$ & $\begin{array}{l}\text { Fogueira da base da } \\
\text { camada de ocupação }\end{array}$ & $2160 \pm 40$ & - & $2310-2040$ \\
\hline
\end{tabular}

* Calibrados por Beta Analytic Radiocarbon Dating Laboratory.

Fig. 5. Quadro de calibração das datações radiocarbônicas dos sítios arqueológicos do Complexo Lagunar de Saquarema.

de Saquarema (camada III), verificou-se uma mudança gradual na economia e na tecnologia dos grupos sambaquieiros.

Esta mudança se referiu à substituição gradual do predomínio dos moluscos do gênero Ostrea (camada II do sambaqui de Jaconé e ocupação do sambaqui de Madressilva) pela espécie A. brasiliana (camada I do sambaqui da Beirada). A mudança nos recursos malacológicos esteve associada à mudança na matriz sedimentar dos sambaquis, observando-se a lenta substituição da matriz conchífera por uma matriz mineral-orgânica. Nesta matriz, de coloração preta, as conchas de A. brasiliana e de outras espécies estavam dispostas na forma de lentes e/ou bolsões inseridos no sedimento preto. Todos os sambaquis deste período passam a apresentar essa configuração estratigráfica (Fig. 7). Soma-se que mudanças nos recursos ictiológicos também foram observadas, com os representantes do genero Micropogonias, sendo substituídos gradualmente 


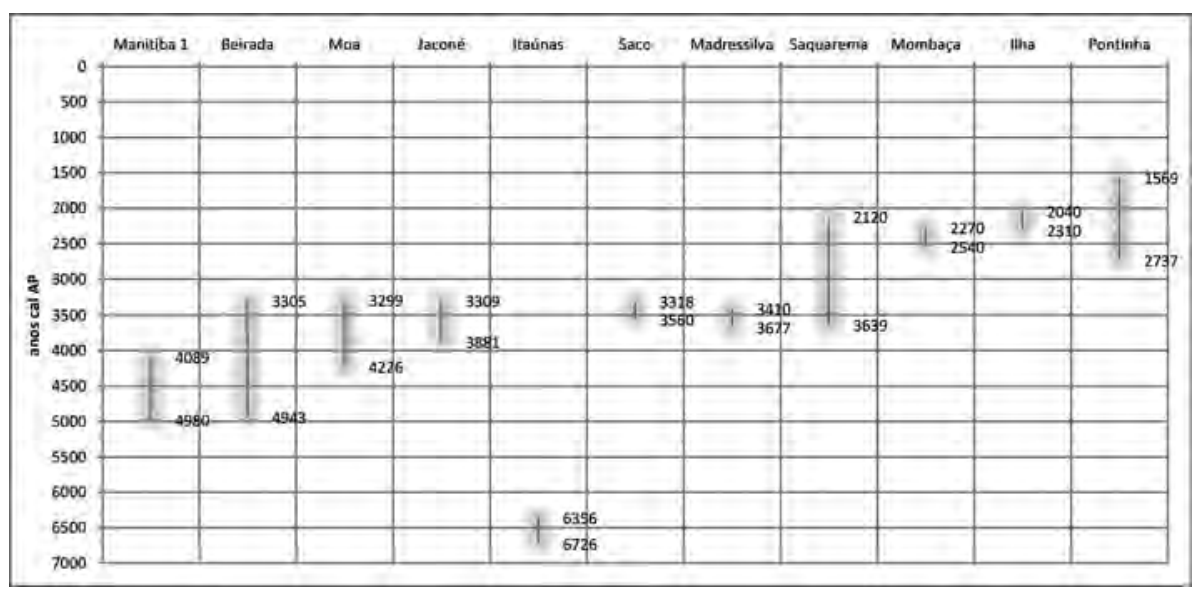

Fig. 6. Gráfico de distribuição das datações radiocarbônicas calibradas dos sítios arqueológicos do Complexo Lagunar de Saquarema.

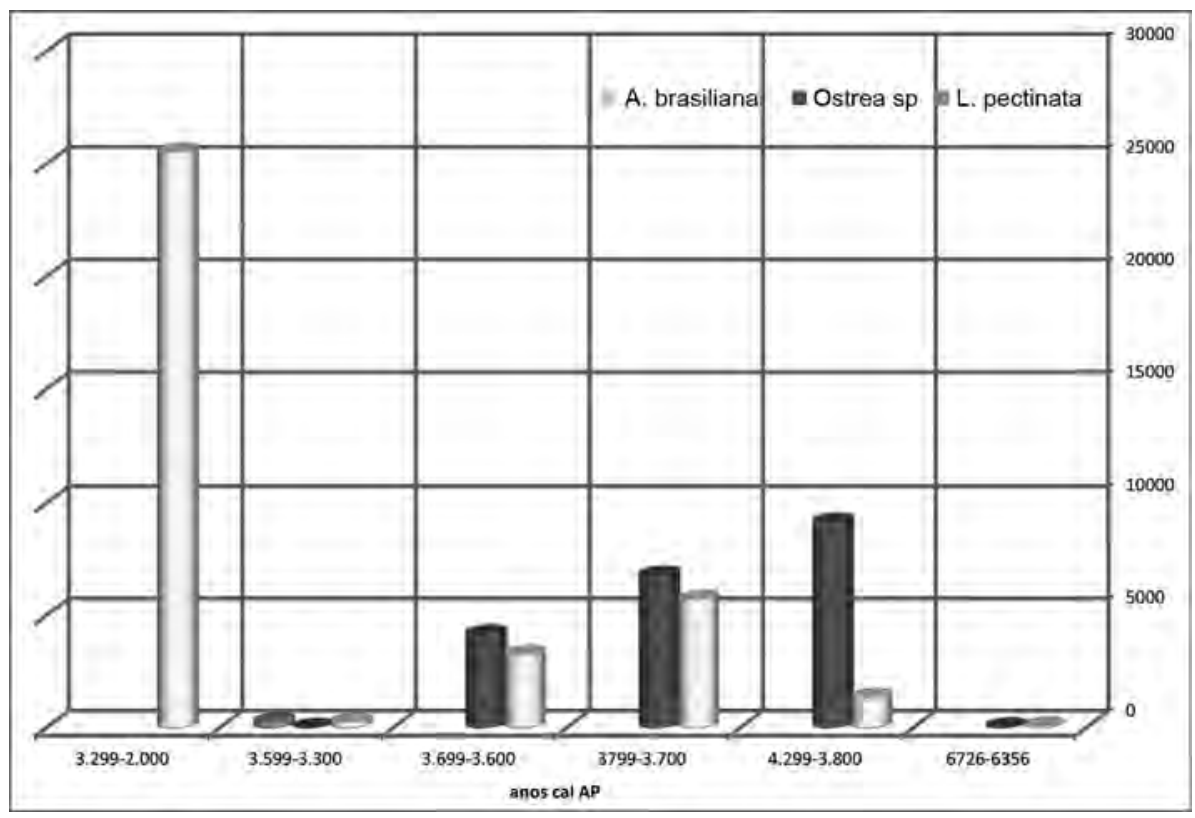

Fig. 7. Gráfico de distribuição dos recursos malacológicos de acordo com os períodos de ocupação do Complexo Lagunar de Saquarema.

(camada I do Moa e camada I do Beirada) por representantes da família Ariidae (camada II de Jaconé e ocupação do sambaqui de Madressilva) (Fig. 8).

Consequente à mudança nos recursos ictiológicos e malacológicos, observou-se uma mudança tecnológica com os espinhos de peixes trabalhados e os seixos utilizados (camadas I do Beirada e Moa e camada II do Jaconé), sendo gradualmente substituídos pelo predomínio das pontas ósseas e dos artefatos confeccionados sobre lascas (Madressilva e camada III do Saquarema), respectivamente (Figs. 9 e 10). Tal mudança reforça que a pesca do genero Micropogonias estava associada à tecnologia dos espinhos de peixes trabalhados enquanto a pesca de representantes da família Ariidae estava associada às pontas ósseas. 


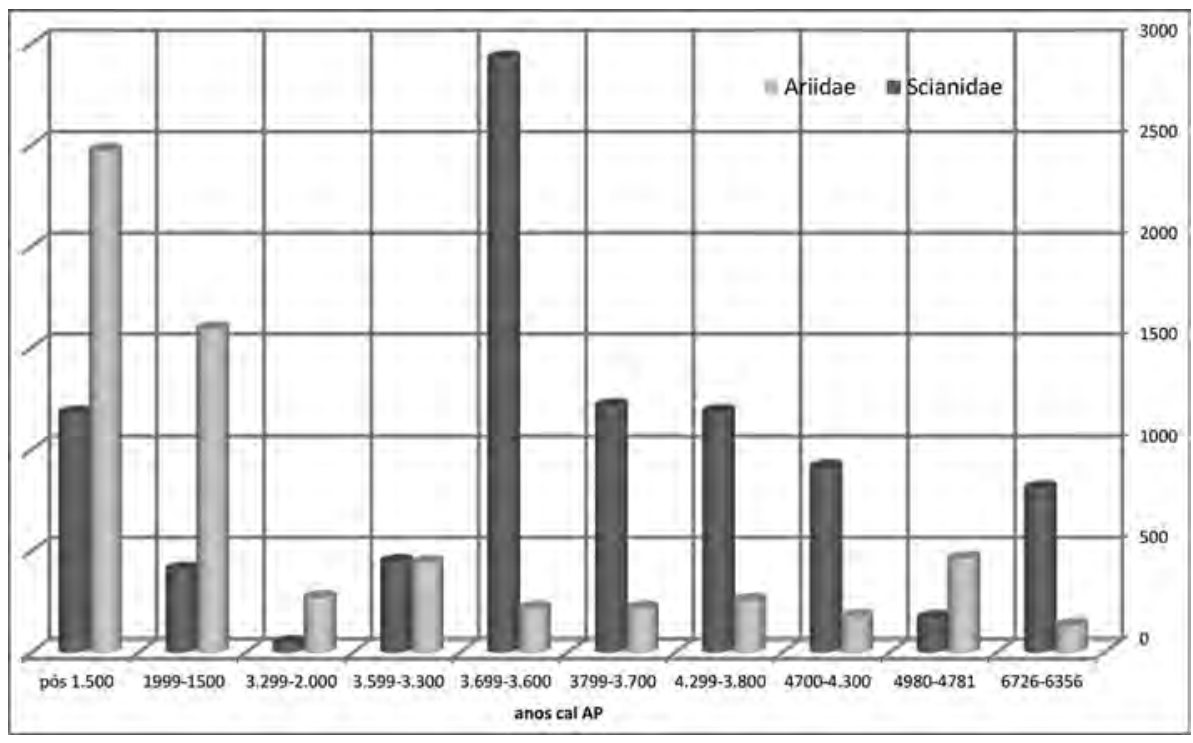

Fig. 8. Gráfico de distribuição dos recursos ictiológicos de acordo com os períodos de ocupação do Complexo Lagunar de Saquarema.

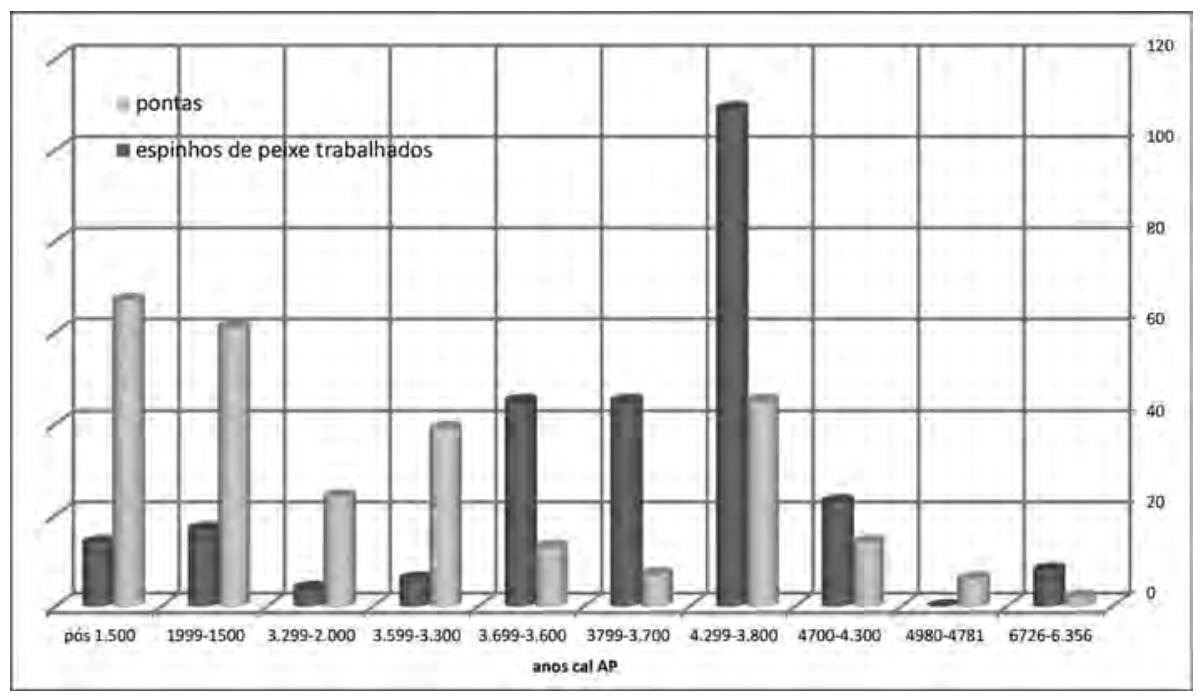

Fig. 9. Gráfico de distribuição dos artefatos ósseos de acordo com os períodos de ocupação do Complexo Lagunar de Saquarema.

No período de 3.599 a 3.300 anos cal, ocorreu o final da ocupação do sambaqui de Jaconé (camada I), a continuação da ocupação do sambaqui de Saquarema (camada II) e o início da ocupação do sambaqui do Saco e, possivelmente, da reocupação do sambaqui de Manitiba I (camada I). Neste momento, a retomada da ocupação da laguna de Saquarema ganhou mais espaço, embora apresentasse um recrudescimento populacional, reiterado por uma queda abrupta nos recursos faunísticos. Interessante observar que desde 3.700 anos cal AP, teve início a ocupação da margem interna da laguna, com a ocupação do sambaqui de Madressilva, e que neste período ganha a presença do sambaqui do Saco. Esta estratégia de ocupação da 
Mudança e colapso no Litoral Fluminense: os sambaquieiros e o s outros no Complexo Lagunar de Saquarema, RJ. R. Museu Arq. Etn., São Paulo, n. 21, p. 71-91, 2011.

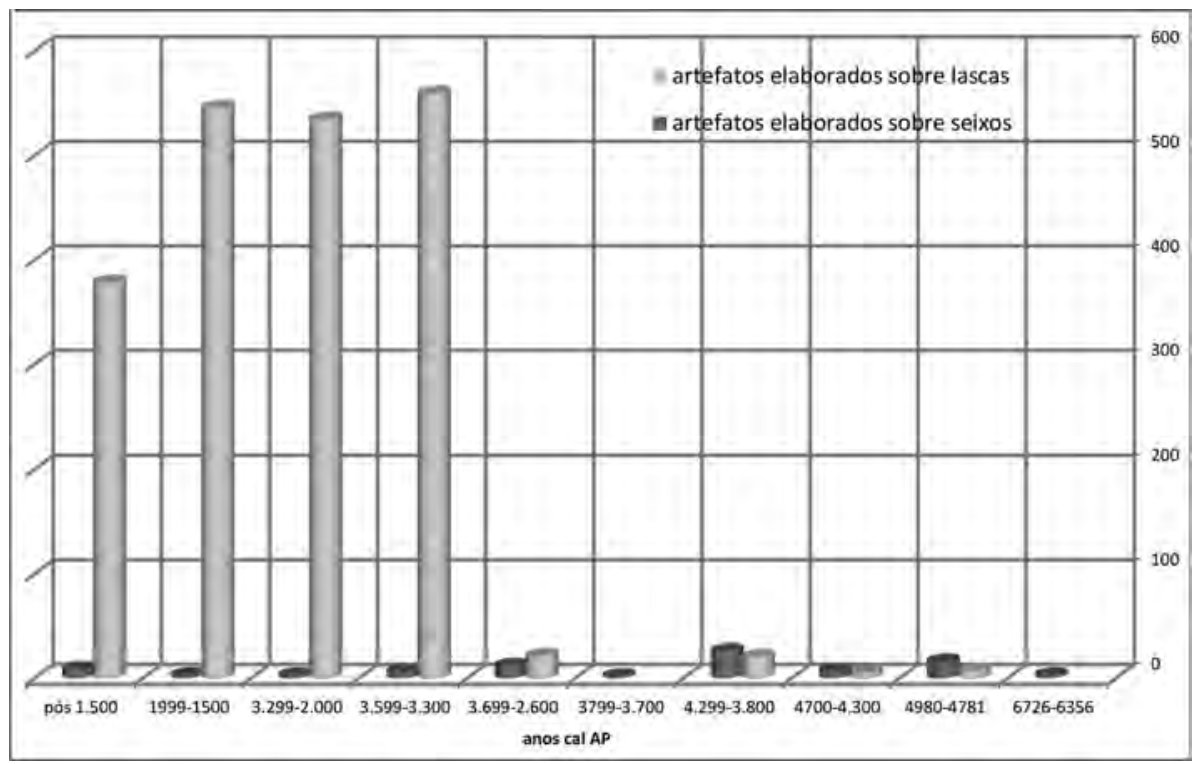

Fig.10. Gráfico de distribuição dos artefatos líticos de acordo com os períodos de ocupação do Complexo Lagunar de Saquarema.

margem interna parece estar relacionada ao domínio territorial pelos grupos sambaquieiros desta porção da laguna que se encontra no sopé das serras que a margeiam. Considerando a queda abrupta na frequência dos recursos aquáticos nos sambaquis da margem externa, verificamos que a margem interna parece ter sido ocupada também em função da maior disponibilidade destes recursos, notadamente dos representantes do gênero Micropogonias.

Considerando a espessura da camada I do sambaqui de Manitiba I, bem como sua composição predominantemente de restos de representantes da família Ariidae, de pontas ósseas e das lascas de quartzo, distribuídas em uma matriz mineral-organica, é certo que o sítio parece ter sido reocupado neste período (embora não esteja disponível datação). ${ }^{1}$

Os representantes da família Ariidae e a espécie A. brasiliana tornam-se dominantes nas ocupações da margem externa da laguna. As pontas

(1) A datação de 3.810 \pm 70 anos AP (4.296-4089 anos cal AP) disponível em Kneip (2001) foi aqui considerada como pertencente ao final da camada II e não ao início da camada I, visto a amostra ter sido coletada entre $60-70 \mathrm{~cm}$ de profundidade. ósseas a as atividades relacionadas ao lascamento do quartzo predominam em todos os sambaquis do período entre 3.599 e 3.300 anos cal.

No período de 3.299 a 2.000 anos AP, os sítios associados à pesca e à coleta de moluscos, identificados no Agrupamento B foram Saquarema (camada I), Pontinha (camada IV), Mombaça I (camada II e I) e Saco. Continuou a ocupação da margem interna da laguna com a ocupação do sambaqui de Mombaça I. Manteve-se o predomínio da tecnologia de pontas ósseas e dos artefatos confeccionados sobre lascas; manteve-se, também, o predomínio dos recursos oriundos da pesca de representantes da família Ariidae e da coleta de A. brasiliana. Contudo, a presença de deste molusco foi observada em lentes e bolsões, distribuídos na matriz mineral orgânica (camada I do Mombaça, camada I do Saquarema, camada I do Manitiba I e camada IV do sambaqui da Pontinha).

O sítio Ilha dos Macacos, datado de 2.3102.040 anos cal AP, marcou a entrada de grupos interioranos em território sambaquieiro. Portadores de uma tecnologia de lascamento de quartzo, da exploração de recursos pesqueiros, e da tecnologia de fabricação de pontas ósseas, 
esse grupo se implantou exatamente entre os sambaquis de Manitiba I e Jaconé, no período em que esses sítios foram abandonados. A formação de uma camada arenosa preta, com aproximadamente $20 \mathrm{~cm}$ de espessura, demonstrou o desenvolvimento de múltiplas atividades, inclusive com presença de estruturas funerárias crematórias, o que indica que o sítio era um espaço habitacional. A presença de cerâmica só foi verificada na superfície do sítio e se constituía em raros fragmentos de cerâmica simples.

No período entre 1.999 e 1.500 anos cal AP apenas o sambaqui da Pontinha estava ocupado (camadas III e II), não tendo sido identificado outras ocupações de grupos com economia de pesca e coleta de moluscos. Contudo, as camadas estratigráficas do sambaqui da Pontinha parecem indicar um gradual aumento na frequência dos artefatos, nos recursos ictiológicos e na densidade populacional. Considerando a estratigrafia do sambaqui da Pontinha, a espécie A. brasiliana encontrava-se dispersa na matriz mineral orgânica e não mais em bolsões e/ou lentes.

No período pós 1.500 anos cal AP, a camada I do sambaqui da Pontinha se caracterizou pelo abundancia dos artefatos, apresentando aumento abrupto na frequência das lascas e a retomada de fabricação dos artefatos polidos (laminas de machado), estes não observados desde 2.700 anos cal A.P. Também apresentou aumento abrupto da indústria óssea, com o ressurgimento da tecnologia de espinhos de peixes trabalhados, embora as pontas ósseas predominassem. Observou-se aumento abrupto também na frequência de mamíferos de pequeno, médio e grande porte, da pesca de representantes da família Ariidae (predominantes) e do gênero Micropogonias. Este aumento na produção de artefatos e no consumo de peixes e mamíferos parece indicar uma retomada dos grupos de economia de pesca e coleta de moluscos na região. Contudo, está não seria tão longa. Acreditamos que esta retomada da ocupação da faixa externa da laguna de Saquarema foi interrompida por fatores externos, relacionados à chegada e instalação dos grupos ceramistas na região, que já faziam incursões ao território sambaquieiro desde 2.300 anos cal AP (sítio Ilha dos Macacos).
Assim, se por um lado, este momento evidenciou a retomada da ocupação na laguna de Saquarema, a partir de uma nova ordem socioeconômica, com a absorção das mudanças engendradas no seio da sociedade sambaquiana e introduzidas pelo contato com grupos ceramistas, por outro lado marcou o fim da ocupação de grupos pescadores e coletores nesta região.

Acreditamos que por suas características composicionais e pela presença de cerâmica na superfície ocorreu a reocupação dos sambaquis do Moa, Saquarema e Saco, neste período.

A introdução da cerâmica (104 fragmentos), relacionada à tradição Una, pode ser observada na superfície do sambaqui do Moa (reocupação?), no sambaqui da Pontinha (camada I), no sambaqui do Saco (reocupação?), no sambaqui de Saquarema (reocupação?) e no sítio Ilha dos Macacos. Em todos esses, o número de fragmentos é reduzido. Nos sambaquis do Saco e Saquarema, foram identificados fragmentos em superfície (Barbosa-Guimarães 2011; Silva 1932).

Após o abandono do sambaqui da Pontinha, ocorrido em data incerta, mas que deve ter sido por volta de 1.200 anos cal AP, não foram identificados mais sambaquis na região do Complexo Lagunar de Saquarema. Sítios cerâmicos relacionados aos grupos antepassados dos Tupinambá como Bravo, Mombaça, Campo e Barroso foram identificados nesta região. Embora não estejam disponíveis dados cronológicos para estas ocupações, estudos realizados no Complexo Lagunar de Araruama colocam a chegada dos antepassados dos Tupinambá por volta de 2.000 anos AP, posicionando-os sincronicamente, ao final da ocupação sambaquiana. Contudo, embora o sítio Morro Grande, localizado em Araruama, apresente uma longa sequência para os grupos Tupinambá na Região dos Lagos $(2.600 \pm 160$ AP, 2.200 \pm 70 AP e $1.740 \pm 90$ anos AP) (Buarque 1999; 2009; Buarque et al. 2003), essa sequência apresenta-se isolada, pois a maioria dos sítios se concentra na faixa do contato com o europeu. Por outro lado, a carência de cerâmica característica dos grupos Tupinambá nos sambaquis analisados parece não indicar relação entre esses e aqueles. 
Mudança e colapso no Litoral Fluminense: os sambaquieiros e o s outros no Complexo Lagunar de Saquarema, RJ.

R. Museu Arq. Etn., São Paulo, n. 21, p. 71-91, 2011.

\section{Discussão}

A Região dos Lagos é formada por duas configurações geográficas: o litoral das restingas, lagunas e baixadas e o litoral dos tabuleiros. A primeira, que nos interessa particularmente, apresenta três grandes complexos lagunares (Maricá, Saquarema e Araruama) e foi espaço privilegiado para a implantação de populações nativas desde 6.000 anos cal AP, quando a descida gradual do nível do mar forneceu a região sua configuração atual. Tal privilégio deve-se a sua configuração litorânea, recortada por pequenas baías e enseadas de águas calmas, por praias retilíneas, onde a presença das lagunas é predominante, e pelas planícies de aluvião marinho e fluvial. A vegetação está representada pela Floresta Perenifólia Higrófila Costeira e a Vegetação Litorânea com suas diferentes formações como as existentes nas praias, restingas, dunas e manguezais. A restinga é a vegetação mais representativa, cobrindo toda a planície da região e fornecendo recursos que foram extremamente utilizados pelos grupos nativos adaptados ao modo de vida litorâneos. Ainda hoje resistem pequenas ilhas de matas de restingas originais e que muito auxiliam na compreensão sobre dieta alimentar e modo de subsistência das populações nativas através do desenvolvimento de estudos etnobotânicos e ecológicos.

Estudos arqueobotânicos demonstram que as alterações observadas na vegetação da área do Complexo Lagunar de Saquarema, ao longo da segunda metade do Holoceno, se restringiram à vegetação de mangue, ecossistema mais suscetível às variações ambientais. Tal fato pode ser confirmado pela presença de espécies malacológicas, originárias desse ecossistema, nos sambaquis de Saquarema. Assim, a cobertura vegetal que atualmente se distribui no Complexo Lagunar de Saquarema, floresta ombrófila densa, floresta de baixada, floresta inundada, brejo herbáceo e vegetação de restinga, é a mesma que foi observada para a segunda metade do Holoceno, com variações na presença de mangue (Scheel-Ybert 2000, 2001).

Como a Laguna do Camacho, em Santa Catarina (DeBlasis et al. 2007), a laguna de Saquarema foi ocupada por grupos sambaquiei- ros durante um longo período, sendo espaço de interação entre os grupos nativos que ali habitavam, o que denominamos de epicentro da ocupação sambaquieira. Isso é depreendido a partir da análise locacional que demonstra que os sambaquis estão implantados nos cordões litorâneos externo e interno da laguna. Essa ocupação é estratégica e visava o controle da laguna. Assim, a laguna de Saquarema desempenhava o papel de centro paisagístico no qual as relações socioambientais dos grupos sambaquieiros se desenvolviam.

A instalação de grupo sambaquieiro na porção leste da laguna, através da ocupação do sambaqui de Itaúnas (Camada IV), entre 6.726 e 6.356 anos cal AP, demonstra que um grupo com domínio de tecnologia voltada à exploração do ambiente litorâneo alcançou o litoral em momento recuado, antes do ótimo climático. Contudo, não somente o domínio do aparato tecnológico demonstra a intimidade destes grupos com o ambiente costeiro, mas a prática de edificação de mounds conchíferos, e dos eventos funerários associados, também já constava na bagagem dos grupos ocupantes do sambaqui de Itaúnas, o que corrobora o recuo da ocupação sambaquieira a um período anterior a 7.000 anos cal AP.

Uma primeira mudança na economia dos grupos sambaquieiros foi observada entre 4.980 e 4.700 anos cal AP, quando o predomínio dos representantes da família Ariidae e da tecnologia das pontas ósseas, observado na camada VII do sambaqui de Manitiba I, foi substituído, na camada VI, pelo predomínio da espécie M. furnieri e dos espinhos de peixes trabalhados. Neste mesmo período, a edificação do sambaqui da Beirada reiterou o predomínio de representantes do genero Micropogonias, da tecnologia dos espinhos trabalhados, e do predomínio de moluscos representantes do ambiente de mangue.

Associamos esta mudança aos fatores de ordem ambiental, notadamente ao aumento das chuvas, que pode ter ocasionado a abertura da laguna, permitindo o aumento de salinidade e a consequente diminuição dos representantes da família Ariidae e o aumento do genero Micropogonias. Igualmente, as informações disponíveis 
em Kneip et al. (1989) sobre o predomínio de espécies de moluscos oriundos do ecossistema de mangue, como Ostrea sp e Lucina pectinata (Gmelin), nas camadas IV, III e II, do sambaqui da Beirada, datadas entre 4.943 e 3.763 anos cal AP, reforçam esta hipótese. Neste sentido, os estudos de Scheel-Ybert (2000) sobre o paleoambiente do Complexo Lagunar de Saquarema devem ser relativizados na medida em que propõe que o mangue não teve papel preponderante na ocupação do sambaqui da Beirada. Embora a autora observe que a baixa densidade de vestígios antracológicos de mangue no sambaqui da Beirada possa ser resultado da distancia entre este ecossistema e o sambaqui, os estudos zooarqueológicos desenvolvidos por Kneip et al. (1989), Kneip (2001) e Correa (1989), e os resultados aqui apresentados demonstram que espécies de moluscos oriundos do manguezal tiveram grande representatividade nas ocupações dos sambaquis da Beirada e Manitiba I, entre 4.943 e 3.763 anos cal AP.

Este quadro ambiental com maior pluviosidade, maior aeração da laguna de Saquarema e presença de manguezais, parece ter se mantido, com algumas oscilações, até 3.600 anos AP, quando foi possível observar o início de um período de diminuição gradual na oferta dos recursos ictiológicos com a consequente substituição da pesca de representantes do gênero Micropogonias pela pesca de representantes da família Ariidae. Essa mudança também influenciou a oferta de moluscos oriundos de manguezais e áreas estuarinas (Ostrea sp e $L$. pectinata), causando uma brusca diminuição na oferta destes recursos e um aumento brusco na oferta da espécie A. brasiliana, representante de fundo lodoso e areno-lodoso das lagunas. Novamente, fatores de ordem ambiental relacionados à diminuição da pluviosidade, devido ao reforço das condições semi-áridas, teriam influenciado a mudança na oferta de recursos aquáticos, notadamente das espécies de moluscos oriundos do mangue. Esta hipótese pode ser sustentada através do estudo desenvolvido por Taysaco-Ortega (apud Scheel-Ybert 2000) no qual propõe a existência de cinco episódios de reforço das condições semi-áridas na Região dos Lagos (3.600-3.500 AP; 3.100-3.000 AP; 2.200-
2.000 AP; $1.200-1.100$ AP; 600-500 AP) e dois episódios de forte pluviosidade (2.300-2.100 AP e 700-600 AP).

A lenta transformação no aporte de recursos aquáticos pode ser vista na composição estratigráfica dos sambaquis que passam a apresentar uma matriz mineral-orgânica composta por lentes e/ou bolsões de A. brasiliana. A mudança nos recursos alimentares atingiu também a tecnologia dos grupos sambaqueiros que tiveram que investir mais na produção de pontas ósseas, diminuindo a produção de artefatos confeccionados sobre espinhos de peixes, as denominadas "agulhas”. Soma-se que esta transformação também foi observada na indústria lítica, com o investimento sistemático na fabricação de artefatos confeccionados sobre lascas, em detrimento dos seixos utilizados.

Em termos sociais, essas unidades, embora portadoras de tecnologias predominantemente baseadas em pontas ósseas e lascas, apresentavam, ainda, fortes traços identitários com os grupos sambaquieiros, sendo representadas através das camadas I dos sambaquis da Beirada, Moa e Itaúnas, da ocupação no sambaqui de Madressilva, e das camadas II e III do sambaqui de Saquarema. Contudo, já neste momento outras mudanças, agora de cunho simbólico, também foram observadas: a manipulação de ossos humanos em sepultamento secundário e a introdução da posição do corpo em decúbito lateral, com membros superiores e inferiores fletidos, nos sepultamentos primários (camada III do sambaqui de Saquarema) (Fig. 11).

Essa diferenciação ganha espaço por volta de 3.400 a 2.800 anos cal AP, com a continuação de ocupações no cordão interno (sambaquis do Saco e de Mombaça I) e externo (camada II do sambaqui de Saquarema). O processo de recrudescimento da tecnologia de espinhos ósseos trabalhados e dos seixos utilizados torna-se mais visível, quando não mais estão presentes grupos portadores destas tecnologias.

No período entre 2.800 e 1500 anos cal AP, surge unidades sociais mais diferenciadas, nas quais a matriz sedimentar apresenta apenas conchas de A. brasiliana dispersas no sedimento (camada I do sambaqui de Saquarema, camada I do sambaqui de Manitiba I, camadas III a I 
Mudança e colapso no Litoral Fluminense: os sambaquieiros e o s outros no Complexo Lagunar de Saquarema, RJ. R. Museu Arq. Etn., São Paulo, n. 21, p. 71-91, 2011.

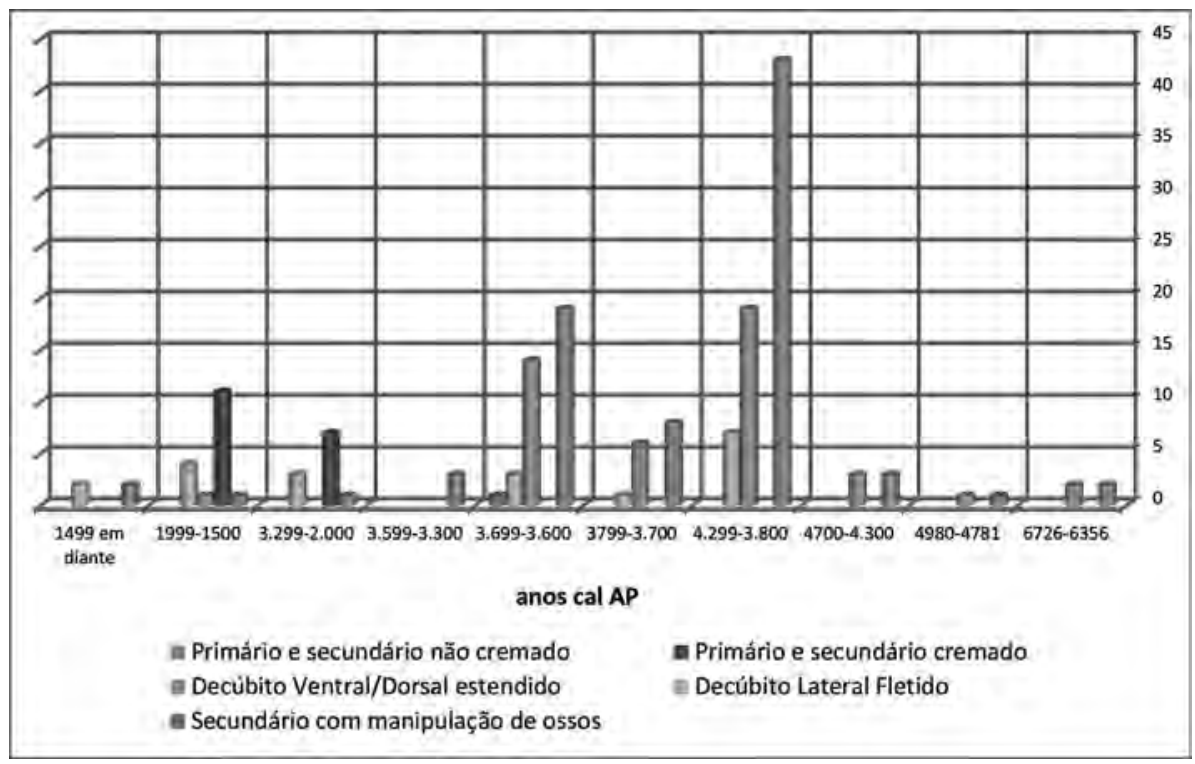

Fig.11. Gráfico de distribuição dos sepultamentos de acordo com os períodos de ocupação do Complexo Lagunar de Saquarema.

do sambaqui da Pontinha). A tecnologia de lascamento do quartzo é primorosa com escolha de matéria-prima de excelente qualidade, o que permitiu uma maior diversidade no conjunto de artefatos líticos.

Esta mudança na economia e na tecnologia dos grupos de pescadores e coletores esteve associada a uma mudança de ordem estrutural, com introdução de novas práticas funerárias. Assim somada à manipulação dos ossos humanos surge a prática de cremação. A prática da cremação dos corpos ocorreu desde o início da ocupação do sambaqui da Pontinha $(2.700$ anos cal AP), tendo sido observada, embora com configuração diferenciada, no sítio Ilha dos Macacos, um sítio lito-cerâmico datado entre 2.310 e 2.040 anos cal AP (Barbosa-Guimarães 2011). Kneip e Machado $(1992,1993)$ demonstram que no sambaqui da Pontinha, os sepultamentos cremados e não cremados não só estão associados cronologicamente, mas culturalmente, com padrões similares de deposição do corpo e acompanhamentos funerários.

A mudança tecnológica proposta para a área piloto, qual seja, o Complexo Lagunar de Saquarema, foi observada, também, a nível macro-regional, no litoral fluminense (Lima
1987; Gaspar 2003; Tenorio et al. 1990). O mesmo pode ser dito sobre a prática da cremação, observada em sambaqui da Ilha de Cabo Frio, num mesmo horizonte cronológico (Tenório et al. 2005).

Consideramos que essas mudanças, na prática funerária e no aparato tecnológico, notadamente em relação ao aprimoramento do lascamento do quartzo, estejam relacionadas ao contato dos grupos sambaquieiros com grupos oriundos do interior, relacionados à tradição ceramista Una, podendo estar representada no sítio Ilha dos Macacos. As datações existentes demonstram concomitância entre essas duas unidades socioculturais, e a presença do sítio Ponta dos Anjos, no cordão interno da laguna de Saquarema, relacionado à tradição Una, e onde foram recuperados dois objetos cerâmicos fusiformes, iguais aos recuperados na camada I do sambaqui da Pontinha, ratifica o sincronismo entre os dois sistemas socioculturais e a existência de contato intersocietal.

Mudanças no universo simbólico, indiretamente inferidas a partir da adoção da prática crematória, estão relacionadas às mudanças estruturais, inseridas na longa duração e consideradas pilares sobre os quais uma sociedade/ 
grupo constrói sua identidade e distingue-se do outro. Tendo isso como premissa, observamos que os grupos sambaquieiros organizaram-se à volta da construção de mounds conchíferos, sob os quais sepultavam os indivíduos que partilhavam regras sociais que diziam respeito, não somente, mas também ao cuidado criterioso com o corpo do morto - cobrindo-o com conchas, escolhendo de posições específicas e, muitas vezes, espargindo corantes ou sedimento avermelhados nos ossos, como nos sepultamentos presentes nos sambaquis de Manitiba I, Beirada, Moa e Itaúnas (sobre preservação do corpo em sambaquis ver Gaspar 2004); à presença de uma parafernália ritual que se compunha de oferendas alimentares e objetos; e à delimitação do espaço funerário com sedimentos coloridos, covas rasas e/ou esteios que sustentavam algum tipo de cobertura, como o observado no sambaqui de Itaúnas (Barbosa-Guimarães et al. 2005/2006).

Nesse sentido, o sambaqui da Pontinha, embora mantivesse a tradição de edificação de mounds funerários, esses não eram mais de conchas, mudança resultante, possivelmente, da gradual diminuição de moluscos, iniciada em períodos anteriores. Por outro lado, o sincronismo entre sepultamentos cremados e não cremados, num mesmo contexto estratigráfico, e de sepultamentos estendidos com ossos espargidos de corante, mostra o peso da longa tradição regional sambaquieira e impede interpretações de ordem prática e simbólica para explicar um possível desenvolvimento local da prática de cremação.

Esses traços caracterizam o sambaqui da Pontinha como uma nova unidade sociocultural, derivada de um longo processo de mudanças ocorridas no seio do sistema sociocultural sambaquieiro, mudanças essas causadas por fatores ambientais e por contato intersocietal possivelmente com grupos da tradição ceramista Una. A presença de fragmentos de cerâmica e de objetos cerâmicos fusiformes, na superfície do sambaqui da Pontinha, iguais aos recuperados no sítio Ponta dos Anjos, bem como na superfície do sambaqui do Moa, Saquarema e Saco, reforça esse contato (Fig. 12).

Entretanto, o contato também trouxe mudanças para os grupos da tradição ceramista Una, a partir da introdução da tecnologia de pontas ósseas (sítio Ilha dos Macacos), de artefatos malacológicos (adornos) e, mesmo, de um espaço edificado, embora não tão visível composto por restos alimentares, sepultamentos fora de urnas e artefatos (sítio Grande do Una, localizado no limite entre a Região dos Lagos e a Planície Fluvial do Rio São João) (Cordeiro 2005).

Assim, o colapso dos grupos sambaquieiros, aqui denominados de unidades geradoras ou originais, como propõe Robrahn-González

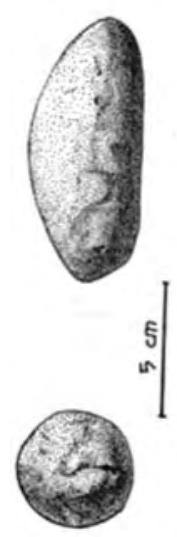

A

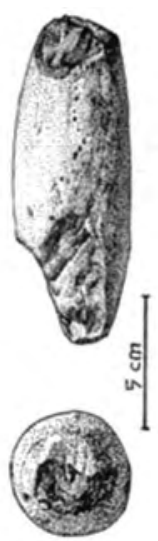

A

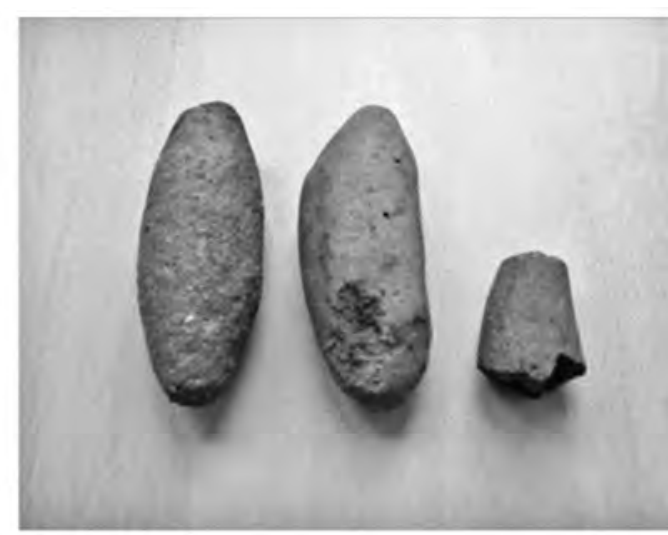

B

Fig. 12. Objetos cerâmicos fusiformes: (A) sambaqui da Pontinha (Desenho de W. Soares de Borba, retirado de Crancio e Kneip 2001); (B) Sítio Ponta dos Anjos (Foto: M. Barbosa-Guimarães). 
(1998), pode ser observado a partir da emergência de novas unidades socioculturais, representadas por um lado, pelos sambaquis do Saco, de Saquarema e da Pontinha, que guardam ainda, traços de sua unidade de origem; por outro, representado pelo sítio Ilha dos Macacos, unidade totalmente nova, que não apresenta traços identitários oriundos dos grupos sambaquieiros originais. Esse sítio, possivelmente, representa o elo de contato entre os grupos da tradição Una e os grupos sambaquieiros. Suas características composicionais, de pouca espessura $(25-30 \mathrm{~cm})$ e de baixa densidade de material (lito-ceramico), associadas à presença marcante de estruturas funerárias de cremação, compostas por ossos humanos extremamente fragmentados e lascas de quartzo, dispostas dentro de pequenas fogueiras (em número de três) concomitantes, nos leva a considerá-lo como um sítio de grupos que ocupavam as porções serranas imediatas à laguna de Saquarema. Poderia, inclusive, estar associado ao sítio Ponta dos Anjos (tradição Una), que se localiza no sopé da serra.

Considerando que o final da ocupação do sambaqui do Moa (camada I), a camada II do sambaqui de Jaconé, a camada I do sambaqui da Beirada, a ocupação dos sambaquis da Madressilva e de Saquarema (camada III), como o início do colapso da sociedade sambaquieira, e o sambaqui da Pontinha como o seu fim, estimamos que o processo de colapso tenha durado, aproximadamente, 1.000 anos.

O modelo aqui proposto de mudança cultural incorporou, assim, os fatores ambientais e as diferenciações resultantes de sua ação derivados do modelo pronapiano de O. Dias e colabora- dores. Embora o esquema de fases e tradições não tenha sido considerado, algumas diferenciações que foram utilizadas para classificar os sítios litorâneos, como a diminuição na oferta de moluscos e existência de sítios com matriz sedimentar diferenciada, foram informações reiteradas em nossa análise.

Por outro lado, o modelo proposto por M. Gaspar e colaboradores permitiu ratificar a existência de um sistema sociocultural sambaquieiro que se estruturou a partir da manutenção de regras sociais que possibilitou a esses grupos o desenvolvimento de uma identidade.

Assim, o sistema sociocultural sambaquieiro do Complexo Lagunar de Saquarema manteve-se por aproximadamente 2.300 anos, com diferenças internas que não comprometeram sua existência. Isso só ocorreu graças aos mecanismos de manutenção relacionados às estruturas, à longa duração. Mudanças conjunturais ocasionaram essa diferenciação interna, e essas estavam possivelmente relacionadas aos fatores de natureza ambiental. Contudo, o contato com grupos interioranos que iniciavam o processo de ocupação do litoral fluminense não só acelerou o processo de diferenciação interna do sistema sambaquieiro como influenciou, diretamente, embora não isoladamente, o seu colapso.

\section{Agradecimentos}

À Dra Angela Buarque pelos comentários, sugestões e revisões. À CAPES, pela bolsa de doutorado, e à Profa Maria Dulce Gaspar pelo apoio do projeto "Soberanos da Costa", financiado pela FAPERJ. 
BARBOSA-GUIMARÃES, M. Change and collapse in Fluminense coast: the sambaquieiros and the others in Saquarema Lagoonar System, RJ. R. Museu Arq. Etn., São Paulo, n. 21, p. 71-91 , 2011.

\begin{abstract}
This research aimed at contributing to understanding sambaqui dwellers who occupied the Saquarema lagoonar system (Rio de Janeiro State, Brazil) between 6.600 and $1.500 \mathrm{cal}$ years BP. The model developed assumes that two factors, environmental change and intersocietary contact have influenced the processes of sociocultural change in the sambaqui society. Parallel to the changes on resources and on mounds edification practice, we can also observe a change on lithic industry technology. New funeral practices were introduced associated with this technological change, such as cremation and the handling of human bones. Around $2.000 \mathrm{cal}$ years BP, this contact, associated to a process that had already been developing inside the fishermen and gathereds groups, marked the beginning of the collapse of the sambaqui society in the Saquarema lagoonar system.
\end{abstract}

Keywords: Social change - Sambaqui Society -Interaction - Social Collapse.

\title{
Referências bibliográficas
}

BARBOSA-GUIMARÃES, M.

2003 Revisitando conceitos: a estrutura social dos pescadores-coletores pré-coloniais. Revista do Museu de Arqueologia e Etnologia, 13: 261- 267.

2011 Um mais um são três. O modelo de mudança sociocultural para o litoral fluminense. In: Cordeiro, J. (Org.) Arqueologia Fluminense. Rio de Janeiro: LLX/LAB/ IPHAN: $32-50$ (prelo).

BARBOSA-GUIMARÃES M.; GASPAR, M.D; CORDEIRO, J.; MANDARINO, M.; GRAF, I.; TABOAS, A.; FARIAS, $M$.

2005/ O Conceito de Longue Durèe e a percepção

2006 de mudança cultural em sociedades igualitárias: o caso da sociedade sambaquiana. Revista do Museu de Arqueologia e Etnologia, 15/16: 445-448.

BUARQUE, A.

1999 A Cultura Tupinambá no Estado do Rio de Janeiro. In Tenório C. (Org.) Terra Brasilis. Rio de Janeiro, Ed. UFRJ: 306-320.

2009 Pesquisas arqueológicas em sítios Tupinambá. In OLIVEIRA, A.P. (org.). Estado da Arte das Pesquisas Arqueológicas sobre a Tradição Tupiguarani. Juiz de Fora, Ed. UFJF: 37-63.
BUARQUE, A.; RODRIGUES-CARVALHO, C.; SILVA, E.

2003 Programa Funerário dos Tupinambá em Araruama, RJ - Sítio Bananeiras. Revista do Museu de Arqueologia e Etnologia, 13: 39-55.

CORDEIRO, J.

2005 Nem cães nem lobos: os guerreiros Goitacás. Pilares da História, 5: 55-68.

CORREA, M.M.G.

1989 O sambaqui da Beirada (Saquarema, RJ): dados culturais, faunísticos e cronológicos. In: Anais do IX Congresso Brasileiro de Paleontologia. Curitiba: 651-665.

CRANCIO, F.; KNEIP, L.M

2001 Artefatos e matéria-prima. Documentos de Trabalho, 5: 35-53.

DEBLASIS, P.; KNEIP, A.; SCHEEL-YBERT, R.; GIANNINI, P.C.; GASPAR, M.D.

2007 Sambaquis e paisagem. Dinâmica natural e arqueologia regional no litoral do sul do Brasil. Arqueologia Suramericana, 3 (1): 29-61.

DIAS, O.; CARVALHO, E.

1980 A pré-história da serra fluminense e a utilização das grutas no estado do Rio de Janeiro. Pesquisas, 31: 43-86.

1995 A tradição Itaipu no Rio de Janeiro. 
Discussão dos tópicos: a questão da imobilidade cultural. In: Beltrão M. C. (Org.). Arqueologia do Estado do Rio de Janeiro. Rio de Janeiro, Arquivo Público do Estado do Rio de Janeiro: 105-110.

ESCÒRCIO, E.; GASPAR, M.D.

2004 Indicadores da diferenciação social e de gênero dos pescadores-coletores que ocuparam a região dos Lagos-RJ. Cadernos do LEPAARQ, II (3): 48-65.

GASPAR, M.D.

1995 Espaço, rito e identidade pré-histórica. Revista de Arqueologia, 8 (2): 221-237.

2003 Aspectos da Organização de um Grupo de Pescadores, Coletores e Caçadores: Região Compreendida entre a Ilha Grande e o Delta do Paraíba do Sul, Estado do Rio de Janeiro. Pesquisas, 59: 1-125.

2004 Cultura: comunicação, arte, oralidade na pré-história do Brasil. Revista do Museu de Arqueologia e Etnologia, 14: 153-168.

HAMMER, O.; HARPER, D.A.T.; RYAN, P.D.

2001 PAST - Paleontological Statistics Software Package for Education, versão 2.02. Paleontology Electronic 4 (1): 1-9.

HASSAN, F.A.

1978 Demographic archaeology. Advances in Archaeological Method and Theory, 1: 49-103.

HODDER, I.

1982 Symbolic and Structural Archaeology. Cambridge: Cambridge University Press.

KNEIP, L.M.

2001 O sambaqui de Manitiba I e outros sambaquis de Saquarema. Documentos de Trabalho, 5: 1-60.

KNEIP, L.M.; MACHADO, L.M.C.

1992 Cremação e outras práticas funerárias em sítios de pescadores-coletores pré-históricos do litoral de Saquarema, RJ. Boletim do Instituto de Arqueologia Brasileira 5: 1-42.

1993 Os ritos funerários das populações pré-históricas de Saquarema, RJ: sambaquis da Beirada, Moa e Pontinha. Documentos de Trabalho, 1: 1-76.

KNEIP, L.M.; CANCRIO, F.; FRANCISCO, B.

1988 O sambaqui da Beirada (Saquarema, RJ). Aspectos culturais e paleoambientais. Revista de Arqueologia, 5(1): 41-54.

LESSA, A.; MEDEIROS, J.C.

2001 Reflexões preliminares sobre a questão da violência em populações construtoras de sambaquis: análise dos sítios Cabeçudas (SC) e Arapuan (RJ). Revista do Museu de Arqueologia e Etnologia, 11: 77-96.
LIMA, T.A.

1987 Pesquisas zooarqueológicas em sambaquis da Baía da Ribeira, Angra dos Reis, Rio de Janeiro. Boletim da Fundação Brasileira para a Conservação da Natureza, 22: $126-32$.

MACHADO, L.C.

1991 Método de reconstituição paleodemográfica: o exemplo do sítio Corondó, RJ. Revista de Arqueologia, 6: 120-136.

RENFREW, C.

1984 Approaches to Social Archaeology. Cambridge: Harvard University Press.

ROBRAHN-GONZALEZ, E.R.

1996 O estudo da interação cultural em arqueologia. Revista do Museu de Arqueologia e Etnologia, Suplemento 3: 31-34.

1998 Regional Pottery-making groups in southern Brasil. Antiquity, 72 (277): 616-624.

SCHEEL-YBERT, R.

2000 Vegetation stability in the Southern Brazilian coastal area from 5500 to $1400 \mathrm{yr}$ BP D-deduced from charcoal analysis. Review of Palaeobotanic and Palinology 110: 11-138.

2001 Man and vegetation in Southeastern Brazil during the Late Holocene. Journal of Archaeological Science, 28: 471-480.

SCHORTMAN, E.M.; URBAN, P.A.

1987 Modeling interregional interaction in Prehistory. Advance in Archaeological Method Theory, 11: 37-95.

SILVA, A.C.S.

1932 El sambaqui de Saquarema (prehistoria de Rio de Janeiro, Brasil). In: Actas do XXV Congresso Internacional de Americanistas. La Plata: 179-183.

STUIVER, M.; REIMER, P.J.

1993 Calib - Radiocarbon Calibration Program, versão 6.2. Radiocarbon, 35: 215-230.

TENÓRIO, M.C.; GASPAR, M.D.; BULCÃO, S.

1990 Pesquisas arqueológicas na praia de Geribá. Revista do CEPA, 17: 221-258.

TENÓRIO, M.C.; AFONSO, M.; SAVI, D.C.; PINTO, D.C.; GONZALEZ, M.M.B.; NAMI, S.; ÂNGULO, A.R; REIMER, P.J.

2005 O sítio ou os sítios da Ilha do Cabo Frio: primeiros resultados. In: Anais do XIII Congresso da Sociedade de Arqueologia Brasileira. Campo Grande, MS.

UCHÔA, D.P.; MELLO E ALVIM, M.C.; GOMES, J.C.O.

1989 Demografia esqueletal dos construtores do sambaqui de Piaçaguera. Dédalo, Publicação Avulsa, 1: 455-470. 
VOUVELLE, P.A.

1993 História e a Longa Duração. In: Le Goff, J.; Nora, O. (Orgs.) A História Nova. Rio de Janeiro, Martins Fontes: 68-97.
WILLEY, G.

1953 Prehistoric Settlement Patterns in The Virú Valley. Bulletin of Bureau of American Ethnology, Washington, DC: Smithsonian Institution, 155: 1-453.

Recebido para publicação em 6 de julho de 2011. 